\title{
Editorial
}

\section{El FMLN \\ que El Salvador demanda}

El FMLN es aún una novedad en la polírica salvadoreña, en parte, porque todavía despierta expectativas esperanzadoras —en quienes piensan que puede resolver los problemas de las mayorías populares - y temerosas -en quienes lo continúan considerando como una amenaza para la propiedad privada y los privilegios ancestrales. Por eso, sus acciones no pasan desapercibidas. La elección de los candidatos a la presidencia y vicepresidencia de la república, además de la curiosidad normal que esta clase de eventos suscita, concentró la atención de la opinión pública por la novedad del proceso, el cual se planteó como un ejercicio de democracia interna. Los candidatos serían elegidos por los delegados de las bases, reunidos en una convención nacional, y no por la dirigencia del partido, tal como es usual en la política salvadoreña.

De esta manera, el FMLN se disponía a rechazar el verticalismo autoritario de la política tradicional y a sentar un precedente sobre cómo practicar la democracia en el interior de un partido político. Sin duda, su ejemplo presentaba buenas posibilidades para convertirse en una contribución importante para la democratización de la política partidista y del país en general. Sin embargo, el proyecto no arrojó los resultados esperados y dejó una sensación de insatisfacción e incluso de frustración en las filas del FMLN, y el efecto transformador que la novedad pudo haber tenido en los otros partidos políticos y en El Salvador se desvaneció, lo que confirmó los prejuicios de aquéllos sobre la democratización de la política.

No obstante el limitado alcance de sus resultados, el intento es importante y las primeras dificultades experimentadas no debieran ser razón para renunciar a continuar insistiendo en la necesidad de democratizar las prácticas de los partidos políticos. Ahora bien, para poder avanzar en esta direc- 
ción es menester analizar las dificultades que el proceso tuvo que enfrentar. Sólo así el FMLN podrá superar sus contradicciones y debilidades, alcanzando la madurez necesaria para entregar a El Salvador lo que éste se merece de un partido de izquierda, comprometido con la democratización y el cambio revolucionario.

\section{El malogro de un buen proyecto}

No se puede desconocer el esfuerzo del FMLN para desarrollar mecanismos institucionales que le permitan ciertas prácticas democráticas en su interior. En contraste con los usos prevalecientes en los otros partidos políticos, el FMLN está empeñado en sustituir las decisiones de los comités centrales o los consejos ejecutivos por una mayor representación de sus bases. Aunque los mecanismos utilizados hasta ahora todavla no garantizan la expresión plena y libre de éstas, es claro que buscan desplazar el poder de decisión de las comisiones de dirigentes a instancias con una representación más amplia de las bases. Este desplazamiento es un indicio prometedor de los intentos del FMLN por institucionalizarse y abrirse a la sociedad, en contraposición a los elitismos y personalismos que caracterizan a los otros partidos políricos. En este contexto, por ejemplo, hay que interpretar la búsqueda de posibles candidaturas fuera de las filas de sus militantes.

Someter a los delegados de las bases, reunidos en una convención nacional, la selección de los candidatos a la presidencia y vicepresidencia de la república es una novedad en la vida política salvadoreña reciente. Unicamente la democracia cristiana lo había intentado antes, pero pronto retornó a los conocidos mecanismos autoritarios y verticales, porque, de otra manera, su dirigencia no podía garantizar el resultado esperado.

Las corrientes que se disputan el control del FMLN estaban más interesadas en asegurar el triunfo de sus candidatos que en discutir y negociar una estrategia electoral y gubernamental.

La convención del FMLN era una oportunidad para presentar un partido unido y dispuesto a acatar la voluntad de la mayoría de sus delegados. Al comienzo del proceso de selección, aquél contaba con los mejores precandidatos disponibles para un partido de izquierda. Ninguno de ellos pertenecía a partido político alguno. Los precandidatos fueron propuestos en su calidad de ciudadanos de reconocida trayectoria social y ética, y por poseer potencial para unificar el partido y atraer votos más allá de sus fronteras electorales. No obstante contar con elementos nada despreciables para contribuir de una manera importante a la democratización de El Salvador, el FMLN no sólo no alcanzó las metas que se había propuesto, sino que, 


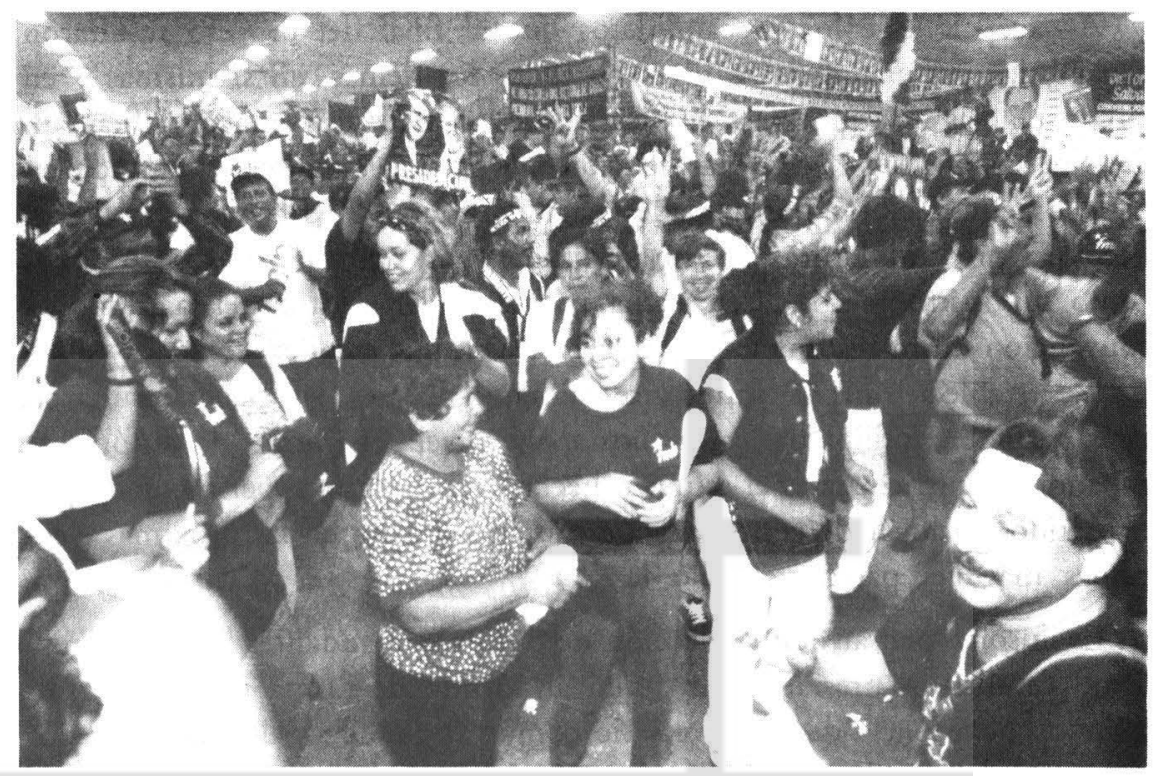

además, alteró las reglas electorales para acomodarlas a las conveniencias de su dirigencia y utilizó a los precandidatos como piezas de su ajedrez político. De esta manera, el FMLN echó a perder una oportunidad histórica.

La elección de los candidatos presidenciales del FMLN quedó atrapada en el conflicto interno que lo divide de forma casi simétrica - al menos a nivel de los delegados a la convención - entre los así llamados renovadores y los ortodoxos o duros. Las votaciones en las que las dos corrientes se disputaron las candidaturas fueron muy cerradas. En el tercer intento se impuso la llamada corriente renovadora por un estrecho margen de 33 votos.

La denominación de las dos corrientes, una como renovadora y la otra como ortodoxa, debe mucho al efecto mediático. En la práctica, los asíllamados ortodoxos no se diferencian ideológicamente de los renovadores; al menos no a nivel de plan de gobierno, pues ambas dirigencias habrian llegado a un acuerdo sobre él; aunque siempre queda la posibilidad de que existan agendas ocultas, las cuales, al no haber sido discutidas abiertamente, contradirían los esfuerzos democratizadores. Por el otro lado, los as! llamados renovadores practican los misinos métodos que sus adversarios ortodoxos. Supuestaraente, éstos últimos serían más reticentes a introducir los cambios modernizadores propuestos por los renovadores; pero, de hecho, son éstos los que, al ganar las candidaturas presidenciales, se resisten a abrir las estructuras del partido a otros sectores sociales y politicos -incluida la Unión Social Cristiana, con la cual intentan integrar una coalición. Esto reduce el alcance de la división a una simple pugna por el poder en el interior del FMLN. 
A excepción de los precandidatos que al final del proceso resultaron electos, las personalidades e ideas de todos los demás, en sí mismas y en circunstancias más unitarias, hubiesen sido aceptadas sin mayor dificultad. De haber sido éste el caso, la atención del partido se hubiese centrado en aquéllos con mejores posibilidades para derrotar a ARENA en las urnas. Pero las precandidaturas fueron utilizadas por renovadores y ortodoxos como un instrumento de su lucha por el poder dentro del partido. La convención misma es una muestra de ello. Más que atender a razones políticas, se establecieron posiciones y se midieron fuerzas, las cuales resultaron estar bastante equilibradas, al menos a este nivel. El triunfo de la fórmula ganadora es pírrico, pues el esfuerzo hecho y el desgaste experimentado por el partido, en lugar de contribuir a asegurarle el éxito en las próximas elecciones, más bien parecen alejarlo de él.

Es ilusorio pensar que la elección de dos ex comandantes "renovadores" como candidatos presidenciales unirá al partido de forma mecánica. Aun cuando la existencia de un adversario común llegase a amalgamar a las dos corrientes durante la campaña electoral y el FMLN ganase las elecciones de marzo de 1999, la pugna reaparecerá con toda probabilidad en el momento de conformar el nuevo gobierno, poniendo en peligro su consistencia. No obstante haber reconocido su derrota con elegancia, lo cual es muy de alabar, es inevitable que los ortodoxos se consideren vencidos y los renovadores, triunfadores. Para superar este sentimiento y llegar a acuerdos básicos sobre los cuales apoyar las estrategias electoral y gubernamental, es necesario colocar los intereses del partido y del país por delante de las ambiciones particulares.

En este contexto hay que situar la serie de desaciertos que malograron el proceso para seleccionar a los candidatos presidenciales. El primero de ellos fue la falta de claridad sobre la relevancia de la estrategia electoral y, eventualmente, también gubernamental. Cuando ARENA designó a su candidato a la presidencia de la república, el FMLN prometió un plan de gobierno. Presionado por la salida temprana de la candidatura oficial, el FMLN reaccionó señalando la importancia de la plataforma sobre las candidaturas, es decir, de lo estructural sobre lo personal. Sin embargo, su dirigencia aún no ha superado este atavismo de la política salvadoreña y, por consiguiente, también en su seno, los candidatos parecieran ser bastante más importantes que las estrategias. De hecho, el plan de gobierno del FMLN ha pasado desapercibido, tanto dentro como fuera de él.

Las corrientes que se disputan el control del FMLN estaban más interesadas en asegurar el triunfo de sus candidatos que en discutir y negociar una estrategia electoral y gubernamental. Así se explica que a lo largo del proceso, muchos hayan adoptado actitudes que pusieron en entredicho la pretendida vocación democrática del partido e incluso que estuviesen dispuestos a 
pasar por encima de sus propios mecanismos institucionales. Al final, los delegados a la convención aparecieron más interesados en ganar su elección particular, que en demostrar a la sociedad salvadoreña que son una alternativa política madura y democrática con potencial para gobernar la nación.

El segundo desacierto es la inexistencia de mecanismos para superar las diferencias internas. El FMLN desaprovechó un momento trascendental del proceso político para mostrarse como una institución abierta, tolerante y madura. El orden, la disciplina y las manifestaciones de compañerismo que prevalecieron en las primeras horas de la convención fueron luego opacadas por la intolerancia, la agresión verbal y el fanatismo maniqueo, proyectando una imagen caótica que muchos interpretan, sin más, como una advertencia seria de cómo el FMLN enfrentaría los conflictos nacionales si llegase al poder del Estado. Algunos de sus dirigentes se esforzaron por explicar esta incómoda situación y la atribuyeron a la exaltación normal, característica de esta clase de situaciones, pero las implicaciones de lo sucedido no son tan sencillas como ellos pretenden, porque estas actitudes fueron adoptadas no sólo por elementos de la base del partido sino también por sus delegados, entre quienes había varios diputados. Una vez desatada, la dinámica polarizante quedó fuera del control de la dirigencia del FMLN. Entonces, el activismo polírico panfletario desplazó a la madurez política.

El FMLN, fiel reflejo de la izquierda latinoamericana, ha demostrado tener poca noción del tiempo político. Ocupada en sus disputas internas, a la dirección del FMLN no parecen preocuparle mucho los plazos a los cuales debe ajustarse su estrategia política, presuntamente orientada a triunfar sobre su adversario político principal.

Las diferencias internas no sólo quedaron bien establecidas, sino que, además, se hizo evidente la no existencia de mecanismos para el diálogo abierto y tolerante que, sin herir ni resentir, pudiera dirimirlas. En lugar de ello, el grito y el insulto prevalecieron sobre el diálogo y la propuesta, lo cual fue un error político grave. La inflexibilidad y la intolerancia no son las mejores actitudes para superar las diferencias de cara al país. Aunque no se puede juzgar a todo el partido por la actuación de una parte del mismo, la intolerancia, la agresividad y la desconfianza se generalizaron de tal manera que no sólo pusieron en peligro la elección de los candidatos, sino que amenazan la unidad del partido a mediano plazo.

El tercer desacierto, muy relacionado con el anterior, consistió en querer solventar la división interna del partido con un mecanismo de orden exter- 
no, orientado a una elección nacional. Lo que se cuestiona no es la vocación democrática del FMLN, sino la utilización de un medio típicamente electoral para solventar una diferencia interna, reduciendo al mismo tiempo sus posibilidades, ya de por sí limitadas, de triunfo sobre ARENA. El FMLN confundió las perspectivas. La elección de una fórmula presidencial integrada por dos ex comandantes "renovadores" puede satisfacer a una buena parte de sus bases, pero no a un electorado nacional que busca alternativas novedosas a la clase política actual. El FMLN cuenta con una porción importante del electorado; pero para derrotar a ARENA le hacen falta más votos. Por consiguiente, debe captar más electores, convenciéndolos para que le den su voto y lo apoyen, en el caso de triunfar. Aquí es donde nuevas alternativas capaces y frescas puede ser determinantes. Al decidirse por dos ex comandantes renovadores, el FMLN, más que confirmar ante la sociedad salvadoreña su vocación democrática, muestra su falta de sintonía con los tiempos y las realidades políticas del país.

\section{Poca claridad conceptual y excesivo voluntarismo e ideologización}

El FMLN no sólo experimenta dificultades en su unidad interna, sino que también tiene problemas con algunos conceptos básicos. En un sentido, esto último es excusable por su falta de preparación y experiencia en las lides políticas; pero, en otro sentido, cabe exigirle la madurez política que las circunstancias de El Salvador piden. En su afán por contribuir a la democratización de la vida política salvadoreña, el FMLN no clarificó suficientemente sus ideas antes de iniciar el proceso de selección de sus candidatos, lo cual lo llevó a improvisar, depositando una confianza excesiva en sus propios recursos. Improvisar es correr un albur que, a veces, es inevitable; pero una convención nacional que quería mostrarse como ejemplo de democracia interna por parte de un partido político importante no puede quedar abandonada a la improvisación, sin correr el grave riesgo de que acabe en un fiasco, que fue lo que, en efecto, sucedió.

El FMLN ha confundido democracia con convención nacional y elecciones primarias. La democracia es un medio para ordenar la vida colectiva a través de normas establecidas, reconocidas y respetadas por todos como tales, mientras que la convención es un recurso para proclamar candidaturas, seleccionadas por medio de mecanismos más o menos democráticos —o programas de gobierno, consensados de antemano por las instancias internas de los partidos políticos. No es norma general utilizar la convención para elegir candidatos presidenciales y mucho menos para discutir y aprobar un plan de gobierno. La razón es sencilla, su estructura no permite que los delegados discutan, decidan y voten con madurez política. Para eso están las llamadas elecciones primarias, de las cuales hay modalidades diversas, pero todas ellas coinciden en permitir —unas más que otras, claro está- que las bases de los partidos políticos expresen su voluntad respecto a los aspirantes 
a las candidaturas. El triunfador de las primarias es proclamado en la convención, la cual, además, celebra su victoria.

En su deseo por fortalecer la democratización interna, el FMLN ha forzado los mecanismos a su disposición. Primero intentó utilizar la convención para elegir a sus candidatos presidenciales $-\mathrm{y}$ someter a consideración de los delegados su plan de gobierno-, y lo consiguió sólo en el tercer intento; pero es que, además, preterndía algo todavía más ambicioso $-\mathrm{y}$, sin duda, contradictorio-, zanjar sus diferencias internas con dicha elección. La convención no era el sitio adecuado para ninguna de las dos cosas y los resultados son prueba de ello. Con todo lo importante que pueda ser, la democracia tiene límites. Pareciera que a base de insistir en la democratización de El Salvador se ha llegado a creer que posee la solución para todos sus problemas. Es la misma actitud que se tiene respecto al mercado. Por lo tanto, a ninguno de los dos debe pedírsele lo que no puede dar. Al desconocer estos límites, el FMLN mitificó la democracia, necesitó tres intentos para elegir a sus candidatos, confirmó el argumento esgrimido por los otros partidos políticos para no seguir su ejemplo, y empañó su imagen al no entregar lo prometido en el tiempo previsto.

La decisión de incluir en la fórmula presidencial a una mujer es buena en sí misma, porque fuerza la apertura de espacios para la mujer en el campo político. El FMLN se ha distinguido por ser uno de los partidos de izquierda del área centroamericana que más espacio ha abierto a la participación de la mujer en su actividad polírica. En consecuencia, el partido elevó a reglamento que entre los candidatos a la presidencia y vicepresidencia de la república debía haber una mujer. Pero esta disposición complicó el

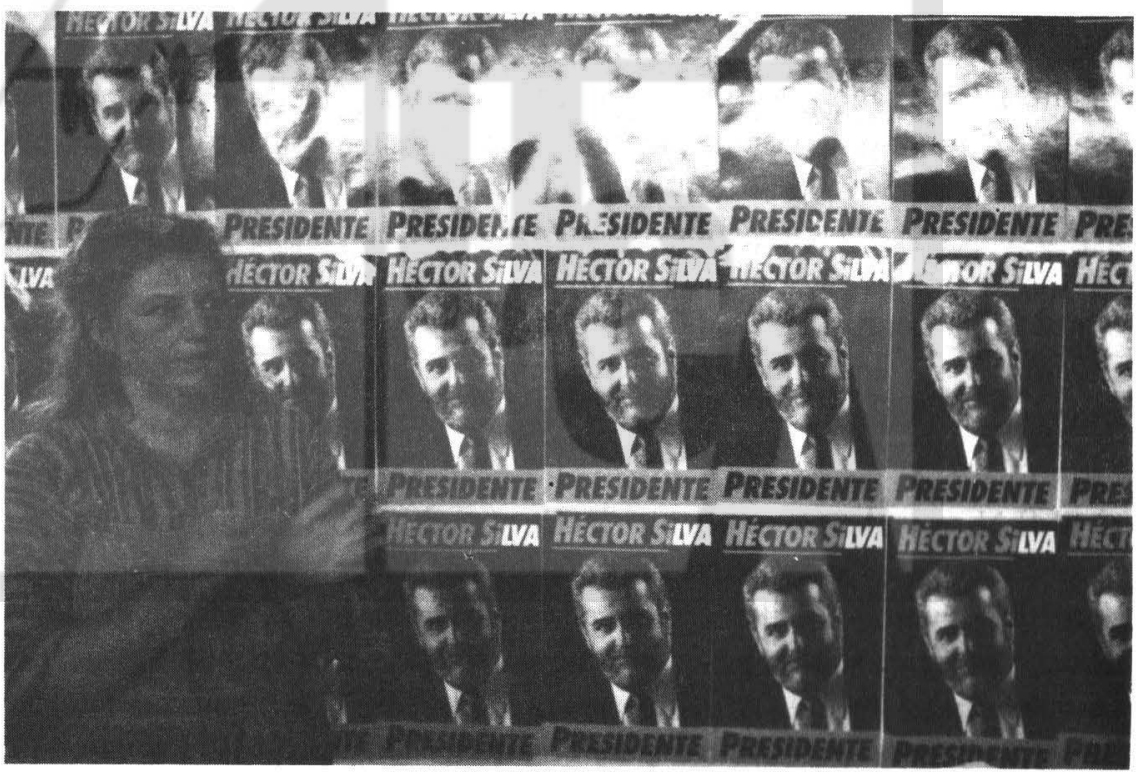


primer intento de elección, dejando el proceso en una posición insostenible. El FMLN no supo encontrar el mecanismo adecuado para concretizar este compromiso con la mujer. A esto hay que agregar que algunos dirigentes utilizaron la dimensión de género para enmascarar el fanatismo con el cual las dos corrientes se disputaban el control del partido, así como también los resentimientos personales de algunas de sus dirigentes. En la medida en que la presencia de una mujer en la fórmula presidencial ha sido utilizada para defender intereses o ambiciones políticas particulares o para reivindicar viejos rencores personales, se ha hecho un flaco servicio a la lucha feminista y al mismo FMLN, que se acaba proyectando como un partido cuya dirigencia pone a su servicio causas importantes.

Así, pues, la pugna por el poder interno ha llevado al FMLN a un nivel de ideologización tal, que le ha imposibilitado analizar la realidad nacional con objetividad.

El FMLN, fiel reflejo de la izquierda latinoamericana, ha demostrado tener poca noción del tiempo político. Ocupada en sus disputas internas, a la dirección del FMLN no parecen preocuparle mucho los plazos a los cuales debe ajustarse su estrategia política, presuntamente orientada a triunfar sobre su adversario políicico principal. La despreocupación por el tiempo lleva aparejado cierro desinterés por la población y la realidad política misma. Esto ha llevado a que el FMLN se cree expectativas falsas y a que no pocas veces haya adoptado posturas irracionales. La convención puso en evidencia el mundo ilusorio en el cual la dirigencia del FMLN se mueve. Mientras ésta se esforzaba por convertir el fiasco de la convención en un triunfo de la democracia, la población percibía un FMLN debilitado por conflictos internos, ocasionados por las ambiciones de los grupos que medran en su interior, $y$, lo que es peor, desacreditado, porque, tal como lo dejó ver la convención, en sus filas no prevalecen la armonía y la cordialidad. Esto ha colocado al partido en una situación peligrosa: en sus bases prevalece la confusión y en la opinión pública, su discurso triunfalista y encubridor no encuentra eco. El realismo no ha sido una fortaleza en la izquierda salvadoreña.

A finales de los setenta y durante los ochenta, los grupos que integraron el FMLN se embarcaron en una lucha armada para imponer un proyecto revolucionario socialista, cuya duración no parecía preocuparles. Fue la época de "la guerra popular prolongada". Posteriormente, la entrega de las armas y la transición de postguerra no parecen haber contribuido a crear en su dirigencia la noción del tiempo político. El FMLN cree, equivocadamente, que éste último —que, entre otras cosas, rige los procesos electorales- lo 


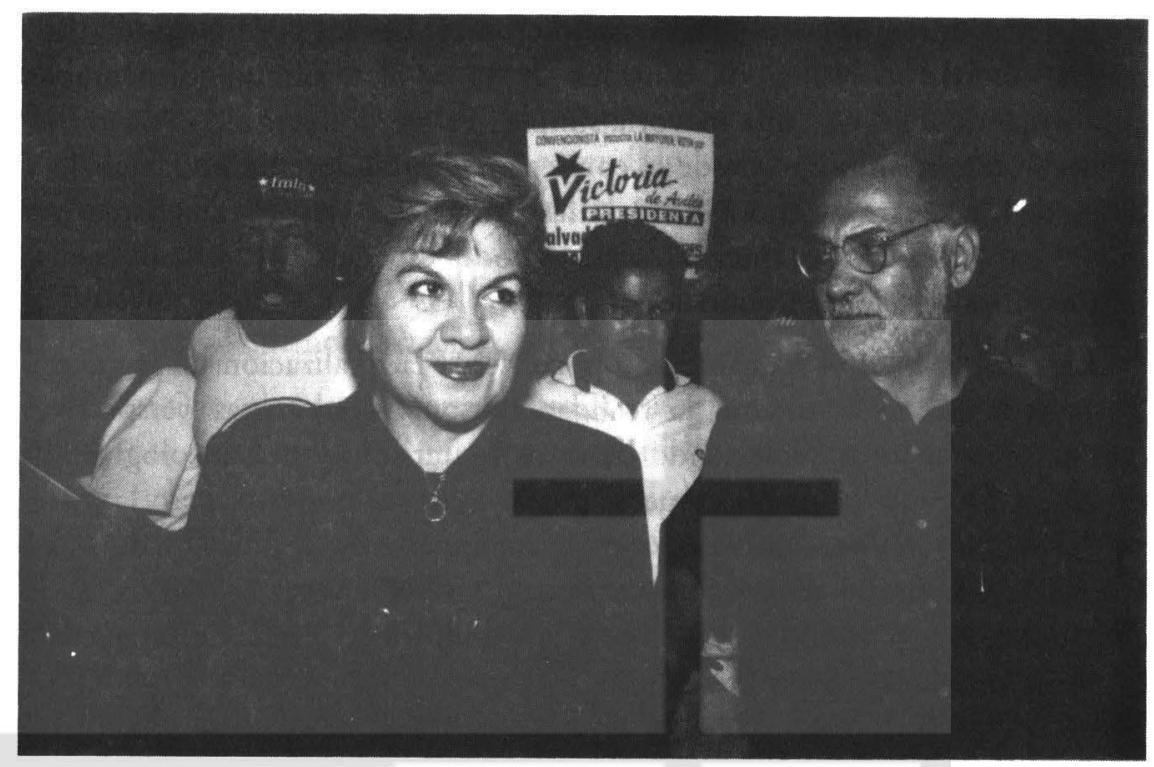

esperará hasta que esté preparado para asumir los desafíos planteados por la realidad nacional actual.

Asimismo, el FMLN desconoce el tiempo de sus simpatizantes y de la sociedad en su conjunto, cuyas expectativas hubiesen sido satisfechas por un partido unido, con ideas claras sobre El Salvador, su gobierno y la campaña electoral, y con candidatos con propuestas atractivas por su novedad y creatividad. En lugar de mirar a quienes se deben por vocación, los dirigentes del partido se han dejado absorber por las pugnas internas, renuentes a ceder la cuota de poder que, según ellos, la historia les habría entregado. Tanto los renovadores como los ortodoxos se consideran depositarios de las mejores tradiciones del FMLN. Por lo tanto, sólo ellos podrían llevar adelante el proyecto de izquierda de forma legítima. Entregar este privilegio a otros equivaldría a traicionar los principios más queridos del FMLN, es decir, cada una de las dos corrientes se considera dueña del aparato del partido.

Así, pues, la pugna por el poder interno ha llevado al FMLN a un nivel de ideologización tal que le ha imposibilitado analizar la realidad nacional con objetividad. En la primera votación de las precandidaturas presidenciales, las dirigencias de las dos corrientes estaban tan convencidas de su propio triunfo que, concluido el sufragio, desmantelaron la infraestructura e hicieron imposible la segunda ronda, prevista por las normas, y además necesaria, dados los resultados obtenidos en aquélla. Este incidente no pasaría de ser una simple curiosidad si no fuera porque la falsas expectativas de ambas dirigencias se repitieron en la siguiente votación, tanto que aceptaron modificar el reglamento al incrementar el número de votos necesarios para ganar. 
En el tercer intento, los candidatos pudieron ser electos porque ambas dirigencias acordaron reducir la cantidad de votos al mínimo indispensable, conformándose así con una mayoría simple. Tal vez hubiese sido más realista establecer este mínimo desde el comienzo, ahorrándose tiempo, trabajo y desgaste innecesarios. Ahora bien, si las dirigencias erraron tan llamativamente en dos elecciones internas, ¿qué se podrá esperar de sus cálculos sobre las próximas elecciones nacionales?

En esto, el FMLN ha cambiado poco desde la finalización de la guerra. Todavía le cuesta considerar la realidad nacional desde otras perspectivas que no sean la suya, adoleciendo de un voluntarismo y una ideologización excesivas. Durante la guerra cometió muchos errores por esto, pero la certeza del triunfo militar, muy superior a cualquier otra realidad dada hasta entonces, le permitió restarles importancia y no pocas veces ocultarlos. En la actualidad, esta posibilidad no existe y la debilidad del FMLN se encuentra expuesta ante la opinión pública.

\section{El poder debe estar al servicio de las mayorias}

La experiencia del FMLN está mostrando cuán difícil es pasar de un régimen militar a orro civil, de un esquema militar a otro político, de unas prácticas autoritarias a otras democráticas. Lamentablemente, los años de guerra y su verticalismo militar todavía determinan en gran medida el quehacer polírico del FMLN. Es indudable que su intención de democratizar el partido es muy loable, pero ello requiere de un gran esfuerzo renovador. Los seis años transcurridos desde su legalización no parecen haber sido tiempo suficiente como para abandonar la vieja lógica militar, más preocupada de que su quehacer no favorezca al adversario que de hacer aquello que debe hacer por el bienestar de las mayorías salvadoreñas, prescindiendo de si con ello favorece o no a sus contrincantes. Al aferrarse a esta lógica obsoleta, el FMLN pone en entredicho sus intenciones democratizadoras.

No obstante estas dificultades, el FMLN debiera continuar luchando por su propia democratización y la de la sociedad.

En este punto, su responsabilidad es enorme y debiera adquirir conciencia clara de ella, no tanto ante sus bases como ante el país entero, independientemente del resultado de las próximas elecciones.

El FMLN quiso avanzar demasiado rápido: intentó hacer un ejercicio democrático sin tener bien asentados sus fundamentos. A la democracia no se llega sólo de la mano de buenas intenciones o apoyado en una determinación, por más firme que ésta pueda ser, lo cual equivale a un simple voluntarismo. Además de voluntad, hay que considerar obstáculos, tales como la 
resistencia que las estructuras autoritarias del partido mismo y de la sociedad en su conjunto puedan oponer, así como también los fundamentos y recursos con los cuales se puede contar para impulsar un proceso democratizador. El partido no debiera ser entendido como propiedad de aquellos dirigentes que acumularon méritos en el pasado conflicto y mucho menos como una prebenda. En consecuencia, sus dirigentes debieran buscarse entre aquellos miembros que se distinguen por su compromiso con la causa de las mayorías y la democratización.

El ejercicio al cual el partido fue sometido por sus dirigentes resultó desgastante, perdiendo así una oportunidad histórica para impulsar la democratización interna de los partidos políticos y, por lo tanto, de la sociedad. Para ARENA y sus aliados, la democracia es disfuncional y, por eso, ni siquiera intentan democratizar sus estructuras internas. Los intereses que predominan en los partidos políticos no toleran la incertidumbre que conlleva todo resultado democrático; en vez de ello, prefieren asegurar éste, recurriendo a métodos autoritarios y verticalistas. El FMLN, pese a sus intenciones, aún no se ha liberado de esta mentalidad. En realidad, su ejercicio de democratización se malogı́ por no pensar en las elecciones presidenciales o en detentar el poder en favor de las mayorías salvadoreñas, sino en quién controlará el aparato del partido. En vez de preocuparse por llegar al poder para ponerlo al servicio de esas mayorías, se ha ocupa en acumularlo para sí mismo. En lugar de prepararse para la campaña electoral y para un triunfo eventual, planifica la toma del poder en su interior. Dicho de otra manera, pareciera que el FMLN no tuviera otro horizonte que sí mismo.

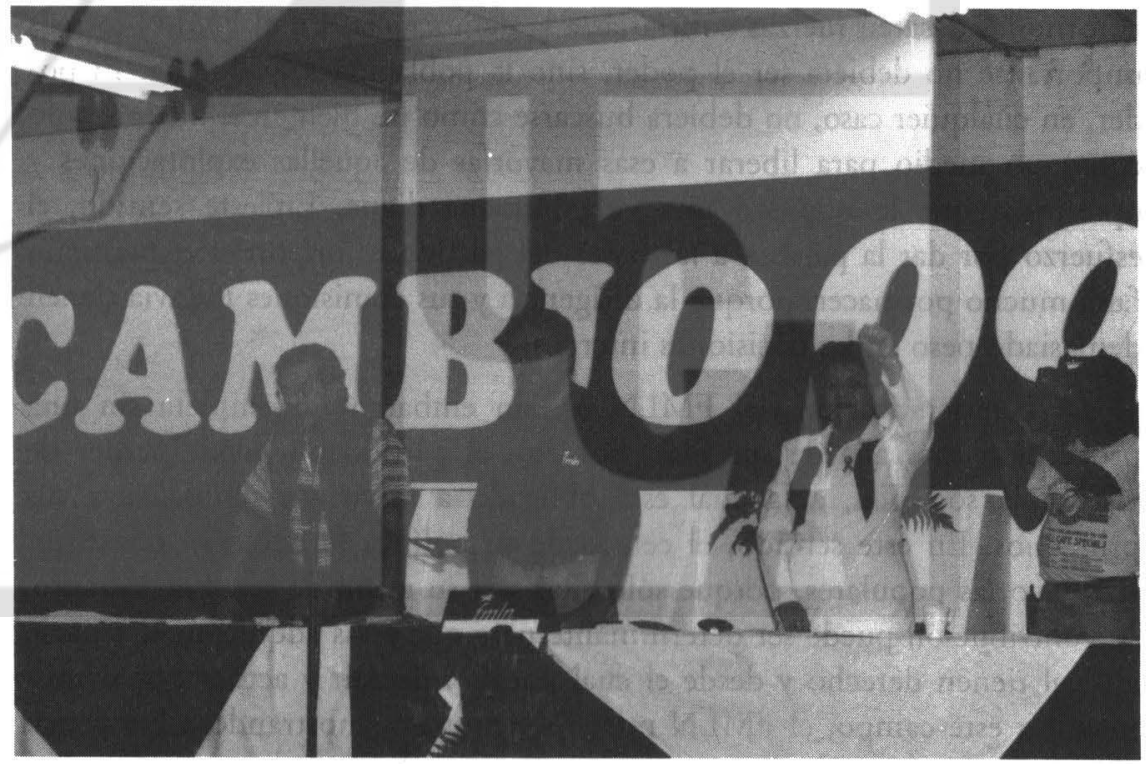


No obstante estas dificultades, el FMLN debiera continuar luchando por su propia democratización y la de la sociedad. En este punto, su responsabilidad es enorme y debiera adquirir conciencia clara de ella, no tanto ante sus bases como ante el país entero, independientemente del resultado de las próximas elecciones. Por lo tanto, le es urgente encontrar un equilibrio saludable entre sus necesidades internas y sus responsabilidades nacionales, entre las ambiciones personales legítimas de sus dirigentes y su vocación transformadora de las estructuras autoritarias e injustas.

Ahora bien, ello sólo es posible si su dirigencia abandona el triunfalismo que la ha caracterizado y se preocupa más por sus propias debilidades, por aprender de sus errores y por ampliar su horizonte, saliendo de sí mismo y colocando su centro en las mayorías salvadoreñas. Como parte de este esfuerzo de apertura y descentración, es indispensable que el FMLN reciba con mejor talante las críticas que se le hacen desde el exterior. Se ha acostumbrado a escuchar sólo a aquellos que le dicen lo que quiere oír, y descartan con demasiada facilidad a aquellos otros que le señalan sus contradicciones y desaciertos. En este sentido, una derrota electoral aplastante podría serle muy beneficiosa si lograra sacarlo del mundo iluso en el cual se ha refugiado; pero no debiera ser necesario llegar a este extremo para introducir los cambios necesarios y esperados. La racionalidad y la érica política debieran imponerse, de una manera natural, en un partido comprometido con las mayorías salvadoreñas empobrecidas.

Si el FMLN no se coloca a la altura de las circunstancias de El Salvador, dando más de sí, no sólo contribuirá a debilitar la esperanza de la mayor parte de su población, que espera mucho de él —a veces, quizás demasiado-, sino que también facilitará la apertura de espacios para que figuras autoritarias desaten fuerzas contrarias a la democracia. En el FMLN lo más importante no debiera ser el poder, sino la población salvadoreńa. El poder, en cualquier caso, no debiera buscarse como un bien en sí mismo, sino como un medio para liberar a esas mayorías de aquellas explotaciones y opresiones que le impiden una vida humana digna. En este sentido, el esfuerzo por dar la palabra a las bases del partido es importante; pero aún falta mucho por hacer, porque la dirigencia y sus comisiones todavía tienen demasiado peso en las decisiones internas.

La democratización del FMLN es, sin embargo, incompleta sin una proyección más allá de sus filas. Por eso, el partido no puede perder de vista a la sociedad, a la cual está obligado a servir sin renunciar a sus principios. En este sentido, el centro de su política lo debieran constituir las mayorías populares, porque sólo ellas son su razón de ser. Por lo tanto, su contribución puede ser determinante para que éstas adquieran el espacio al cual tienen derecho y desde el cual podrían decidir y actuar por sí mismas. En este campo, el FMLN puede ser pionero, mostrando a los demás 
partidos políticos el camino para acercarse a la población y sus necesidades. No se trata de volver a hacer de la organización popular una correa de transmisión de la dirigencia política, sino de promover con convencimiento profundo el surgimiento de una fuerza popular organizada y autónoma, a la cual el mismo FMLN debiera escuchar con suma atención y con cuyas aspiraciones debiera comprometerse, en cuanto partido político.

San Salvador, 9 de octubre de 1998. 